\title{
Advancement of Conventional Anchor Support System through Use of NATM and NMT Approach for Underground Drift Stability \\ ${ }^{{ }^{* 1} V i s h a l ~ M . ~ M e s h r a m, ~}{ }^{2}$ P.P. Dahale, ${ }^{3}$ M.S. Tiwari, ${ }^{4}$ G.G. Manekar \\ ${ }^{1}$ Balaghat Mine, MOIL Limited, Balaghat - 481102, India \\ ${ }^{2,3}$ Department of Civil Engineering, Shri Ramdeobaba College of Engineering and Management, Katol Road, Nagpur - 440013, India \\ ${ }^{4}$ MOIL Limited, Nagpur - 440013, India \\ Email:vishalmmeshram@gmail.com,dahale.p.prasad@gmail.com, tiwarims@rknec.edu, ggmanekar@moil.nic.in
}

Received: 22nd October 2019, Accepted: 31st January 2020, Published: 29th February 2020

\begin{abstract}
In present scenario underground mines of Central India is using conventional supporting with anchoring/bolting system to supports the excavated haulage road and cross cut. In case of geologically disturbed areas concreting with girders is the main support. In routine formations short bolts suffice the purpose. These conventional methods specially concreting is time consuming and hampers productivity. Application of NMT (Novergian Method of Tunneling) and NATM (New Austrian tunneling method) will give the advancement in the support system. Application of both the method will reduce support erecting time and thus the cyclic operation of mining can be accelerated. The cross-section area of Under drift will $6 \mathrm{~m} \times 3 \mathrm{~m}, 4 \mathrm{~m} \times 3 \mathrm{~m}, 3 \mathrm{~m} \times 3$, etc. Conventional concrete support for the area may have required 15 days (5 R-mt span). The same was done by shotcreating with NATM/NMT in just 5 days (5 R-mt span) including lowering of machine and materials.In geologically stable formations applicationof long bolt, short bolt, and anchorage through cable was found to provide requisite support tothe excavated drift.Rock Mass Rating of Bieniawskiand Barton's Q system support calculation methods have been used to calculate support requirementsfor haulage as well as cross cut drifts.
\end{abstract}

\section{Keywords}

New Austrian Tunneling Method, Norwegian Method of Tunneling, Rock Mass Classification (RMC), Rock

Mass Rating, Barton's ' $Q$ ', Rock Bolting (RB), Cable Bolting (CB)

\section{Introduction}

Drift excavation into rock mass has varying degree of problems. Problem related to ground water condition, stresses on rock mass and changes in geologicalproperties. Rocksare discontinuous, non-homogeneous, anisotropic, and their properties are affected by the presence of water. Engineering design associated with the rock mechanics is always challenging because of above mentioned parameters.

In previous century's support system used to be chalk, wooden sleeper, and wooden props.Then these were modified in $19^{\text {th }}$ century with steel arches and girders. First use of rock bolting is reported in 1927 and Weigel in 1943, design the systematic rock bolt design for weak strata. Potvin (1988) develop the design of cable bolting to support rock mass as permanent support. World wide various method based on NMT and NATM application like as Australian methodology, Canadian and Scandinavian methodology, South African methodology etc.[1-5] Most of the mines drift excavation is carried by drilling and blasting methods and roof is supported by steel rod bolting and in weak areas conventional concreting work is done. Cyclic operation of drilling, blasting, supporting, transportation to the shaft and from shaft to surface is time consuming and delay in any one of the parameters affects the productivity. Especially when the bad ground conditions are met, erection of conventional concrete support system slows down the work.Hence there is a need of replacing conventional concrete support method by some other method which is relatively quicker and also economical. NMT (Novergian Method of Tunneling) and NATM (New Austrian tunneling method) help to maintain the safety and economy of excavated drift through speedy work. [6-10]

\section{Scope of Research and Methodology}

Most of the Central India is Contain the Coal and Manganese ore and Rock Formation of the most of the mines available in Maharashtra and Madhya Pradesh is mostly metasedimentary bands with "Typical Schistose rock" containing Gondites and Manganese ore and shale formation on coal region.

Rock Bolting (short anchors) create the pressure beam and artificial arching on the periphery of excavated rock with immediate support after excavation to avoid the fall of rock mass and maintain the size of excavated drift. According to the pressure arching theory, a de-pressured zone directly above the opening will be created due to the stress redistribution after an opening is excavated.

In geologically disturb area, concreting with the girder support is practised which is time consuming and uneconomical. NATM or NMT methods use shotcreating technique to speed up the support system erection. 
Shotcreating workavoids not only falling of small rocks but also act as a permanent support. It is further useful for maintaining the smooth and engineering view of excavated drift.

\section{Methods of Support Systems}

1. Conventional Concreting Method

Initially in the mining mostly used reliable method was concreating the under-ground drift, method is easy but time consuming with uneconomical as compare to time study. In geological disturbed comes inside the underground then suddenly production activity delayed due to time consuming to concreating work. In this work concreating cum short anchors are used to maintain the periphery of the excavated drift.

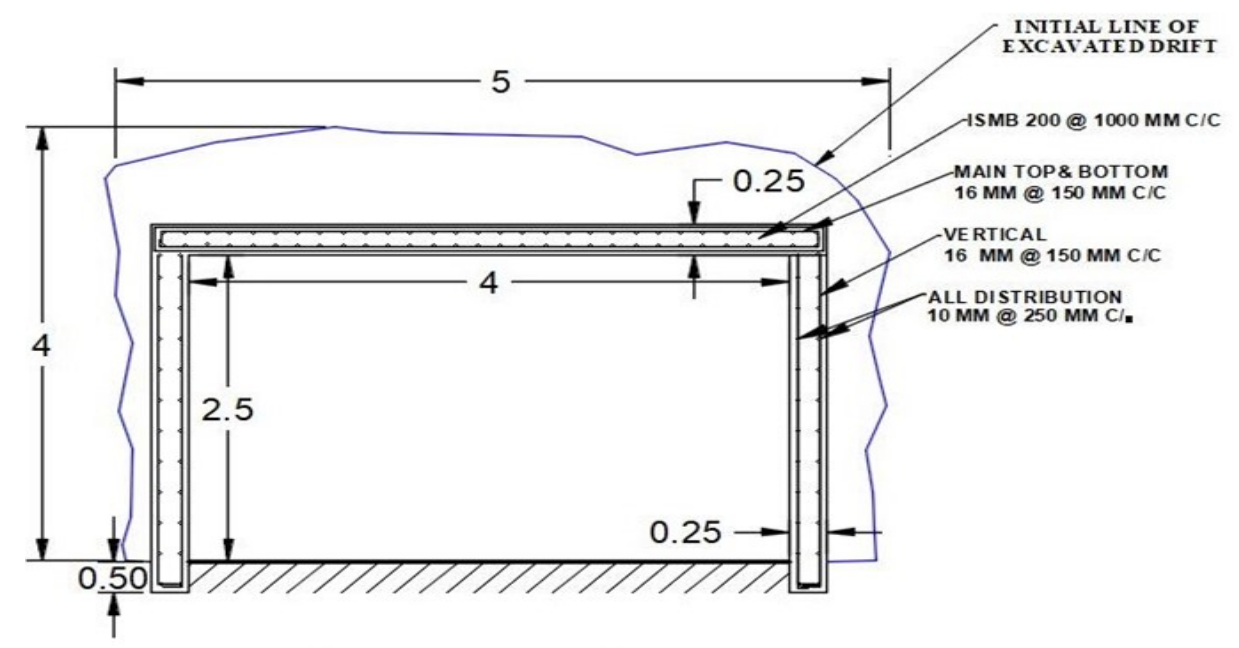

Fig 1: Conventional Section of Portal inside U/G

\section{Details of Novergian Method of Tunneling (NMT)}

Tunneling industry in Norway started in $16^{\text {th }}$ century. Norwegian tunneling owes its origin in $17^{\text {th }}$ century mining industry. Mining industry is back bone of Norwegian economy and many hydro power developments were done in $20^{\text {th }}$ century. Norway has very typical and different type of geological condition with hard rock formation. Which creates fold, fault, tectonic jointing. Drilling and blasting creates the large movement of peripheral rock and create huge fall of rock mass.Even tunnel/drift driven in hard rock will typically have to cross the shear zone(faults) which naturally available in rock such condition also required rock reinforcement like rock bolt and cable bolts. Rock reinforcement methods are strict requirement for quality and durability both initial and final support.

NMT based on the Rock Mass Rating (RMR) and Q-system, both system based on empirical formulation.

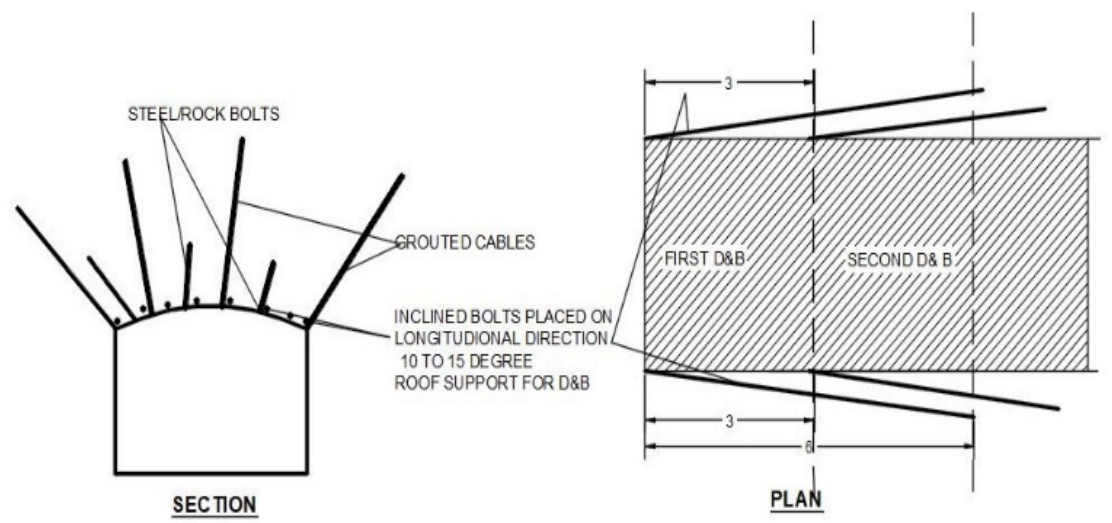

Fig 2: Diagrammatic Representation of NMT

NMT basic data collection for design of tunnel:

- Basic knowledge of ground condition.

- Desk study of maps, visit nearby excavations. 
- Geological mapping, drilling, core sampling, bore log data.

- Monitoring rock stress convergence and deformation.

- Measurement of deformation through extensometer, etc.

Broad principles of NMT

- Rock Mass Classification (RMC): There are many different systems of rock mass classification but Qsystem developed by Barton et al 1974 is widely used.

- Rock mass Stability: Following factor most important for stability of rock mass: 1. Degree of jointing (block size), 2. Joint friction, 3. Stress. Generally, stability of rock mass depends inside the underground depends on stress magnitude in relation to the rock strength. Major stress approaches about $1 / 5$ of compressive strength of rock.

- Failure modes of rock: Shear and bonding failure because block fail and fragmented fail of rock mass occur. The anisotropy of rock mass plays an important role when designing the rock support.

\section{Details of New Austrian Tunneling Method (NATM)}

This method is developed in Austria, since 1970, originally applied in the soft rock and soil having low overburden specially used for urban areas transportation tunnels. NATM is a construction method, which involves simple construction steps and adaptive in nature with economical perspective.Applying sequences excavation of drift made easy to apply shotcrete and reduce the bending moment and shearing forces on the shotcrete member. Large excavated area of drifts/ tunnel can be stabilized by very thin shotcrete members.[1920] It was first used by Rabcewicz in 1962 and worldwide popular. This method has been very useful in complex diversified geological condition where forecasting of rock mass is very difficult.

In this method stability analysis is done by finite element method or codes and numerical computation based on geology and geotechnical data.

\section{Broad Principles of NATM:}

Mobilization strength of rock mass: Peripheral rock of excavated area use as the primary support to tunnel/drift. Shotcrete support: Fall of rock and deformation should be control/minimize by primary layer of Shotcrete immediately after excavation/blasting.

Measurement: Every deformation of excavation must be measured. NATM required to measured sophisticated measurement instrumentation. It is embedded in lining, ground such as load cell, extensometers and relectors.

Primary lining: The primary lining is a thin and applies for to avoid the initial deformation.

Secondary lining: Secondary lining is a combination of soil nails/ ground anchors/ long bolts, short bolts, steel girders, wire mesh.

Closing invert: It is important to complete the load bearing ring.

Rock mass classification: It is the combination of genetic, physical and geological properties of rock. In RMR value gives five classes of rock whereas $\mathrm{Q}$ system provides nine classes of rock. Expert geologist helps to provide the geological parameter for RMC.

Dynamic Design: Applications of anchoring and shotcreting considered the dynamic effects. Support design is flexible and it is based on the type of supporting rock/soil.

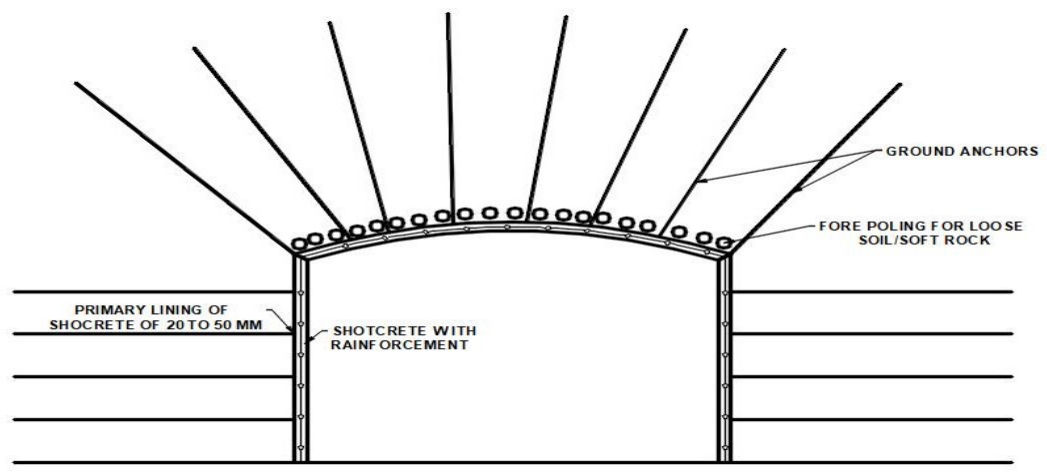

Fig 3: Diagrammatic Representation of NATM

The design of a tunnel through NATM is followed following steps:

- Geotechnical investigation of ground and ground water conditions

- Evaluation of soil and rock mechanical properties, based on test result and on-site experiments.

- Stability analysis of excavated drift and concrete liners with or without peripheral ring/arch of steel/concrete, etc. 
Rock Mass Classification (RMC)

Rock mass classification is the reliable, durable, and empirical scientific approach to design the tunnel, underground mining drift, hydraulic drift etc. Various techniques are available but most commonly used are Rock Mass Rating and Barton 'Q' methods. Following properties of rock help to find out the qualitative form of rock mass.

\begin{tabular}{|c|l|c|l|}
\hline $\begin{array}{c}\text { Sr. } \\
\text { No. }\end{array}$ & \multicolumn{1}{|c|}{ Rock Properties } & $\begin{array}{c}\text { Sr. } \\
\text { No. }\end{array}$ & \multicolumn{1}{|c|}{ Rock Properties } \\
\hline 1 & Uniaxial Compressive Strength (UCS) & 9 & Layer thickness (LT) \\
\hline 2 & Rock Quality Designation (RQD) & 10 & Stresses in rocks (RS) \\
\hline 3 & Spacing of discontinuity (SOD & 11 & Number of joints (NOJ) \\
\hline 4 & Joint roughness value (COD) & 12 & Filler material in joints (AOJ) \\
\hline 5 & Water inflow rate \& pressure (GWP) & 13 & Swelling \& Squeezing of rocks(S\&S) \\
\hline 6 & Orientation of discontinuity (OOD) & 14 & Number of weakness zones (NOWZ) \\
\hline 7 & Weatherability (WD) & 15 & Depth of excavations (DOW) \\
\hline 8 & Faults in rocks (SF) & 16 & Tensile strength of rock \\
\hline
\end{tabular}

Table 1: Rock Properties

Bieniawski's RMR (B-RMR) system is the oldest and widely used system for Underground mines, hydro power drift, tunnel, hilly cuts etc. B-RMR system is divided into six empirical parameters of rock and its rating classified the rock strength and type of support required.

Barton's 'Q' system for rock mass classification was developed at Novergian Geotechnical Institute (NGI) in 1974 and later it was modified. Numerical assessment was based on quantitative classification system by using six parameters.

\section{Test on Rock Sample (For RMR and 'Q' Support System Design)}

\section{Uniaxial Compressive Test}

Uniaxial compressive strength $(\sigma c)[16]$ on rock is widely used to find out Young's Modulus of elasticity (E), Poisson's ratio (u) of the rock material. Also, UCS of rock gives co-relation with cohesion (C) and frictional resistance angle (Ø). Stress - strain curve shows the behavior of rock mass i.e. ductile, elastic and elasto- plastic. To find out the stress strain behavior of rock sample especially for "schistose type" rock, some sample collected from Munsar Mine of MOIL limited on varying depth. Tested sample shows the different stress-strain behavior of change in depth. Figure 4.1 shows the ductile behavior and sudden failure and Figure 4.2 shows the elastomeric properties of the rock with some load carrying strength after failure.
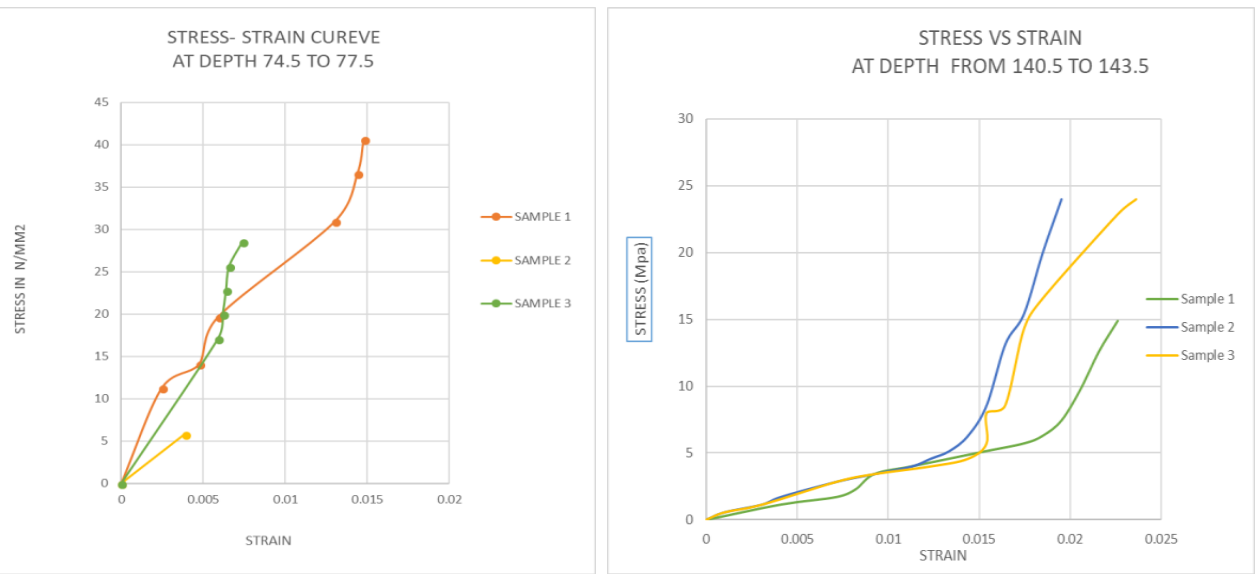

2. Tensile Strength Test (Brazilian Test)

Fig 4: Stress-Strain Curve of Collected Sample

Tensile strength $(\sigma \mathrm{t})[18]$ of rock shows the failure criterion and elastic stress distribution on peripheral area of excavation and rock fracture toughness. In general, for the design purpose, tensile strength of rock is taken as zero. Rock mass response shownby value of tensile strength thus it is considered in the underground excavation. The process of lateral load distribution associated with friction mobilized between the surface of upper beam, was described as arching (Rock Mechanics for Underground Mining, Third Edition by B.H.G. Brady and E.T. Brown). Caving and undercut of the underground opening due to circumferential tensile stresses on periphery of 
the drift. Low in-situ stresses acts due to the gravity on softand medium type of rock and found wedge failure. High in situ stress on rock act due to high strain and intact rock below depth $600 \mathrm{~m}$ and more.

Tensile Strength $(\sigma \mathrm{t})=\frac{2 p}{\pi \cdot D} \mathrm{~N} / \mathrm{mm}^{2}$

\section{Point Load Test}

Point load test carried out for to find out the tensile strength of rock mass and indirect comparison/ estimate with the uniaxial compressive strength of rock mass.

Avg. Tensile Strength $(\sigma \mathrm{t})=0.0675 \frac{P}{D^{2}}$, Avg. Failure load (P), Avg. Dia. Of Sample (D)

\section{Pull Out Test}

Pull out test of rock mass give the bond strength of bolt, grout with rock mass. Pull out test data comes under on site realistic observational data which is realistic for design of rock bolting and cable bolting. And this test carried out on experimental site at Munsar Mine of MOIL limited.

Following type of rock bolt checked for pull out test

i) Plain Mild steel bar with cement grout (Dia. $20 \mathrm{~mm}$ )

ii) Ribbed bar with cement grout (Dia. $20 \mathrm{~mm}$ )

iii) Ribbed bar with resin (Dia. $20 \mathrm{~mm}$ )

iv) Ribbed bar of top wedge with resin (Dia. 20mm)

Plain mild steel bar is use to find out the confining pressure on rock.

\begin{tabular}{|c|l|c|c|c|}
\hline $\begin{array}{c}\text { Sr. } \\
\text { No. }\end{array}$ & \multicolumn{1}{|c|}{$\begin{array}{c}\text { Type of Rock Bolt } \\
\text { (Dia. 20 mm) }\end{array}$} & $\begin{array}{c}\text { Pull load } \\
\text { (Tones) }\end{array}$ & $\begin{array}{c}\text { Bond } \\
\text { Strength } \\
\left(\mathrm{N} / \mathrm{mm}^{2}\right)\end{array}$ & $\begin{array}{c}\text { Ultimate bolt } \\
\text { extension at } \\
\text { failure (mm) }\end{array}$ \\
\hline 1 & Plain Mild steel bar with cement grout & 4.12 & 0.41 & 38 \\
\hline 2 & Ribbed bar with cement grout & 6.80 & 0.676 & 50 \\
\hline 3 & Ribbed bar with resin & 8.20 & 0.816 & 70 \\
\hline 4 & Ribbed bar of top wedge with resin & 10.30 & 1.025 & 75 \\
\hline
\end{tabular}

Table 2: Result of Pull Out Test on Site Inside Under Ground

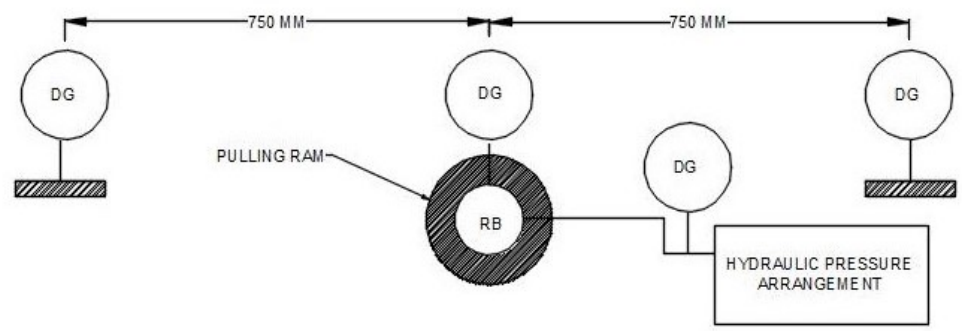

Fig 5: On Site Experimental Pull Out Test Arrangement

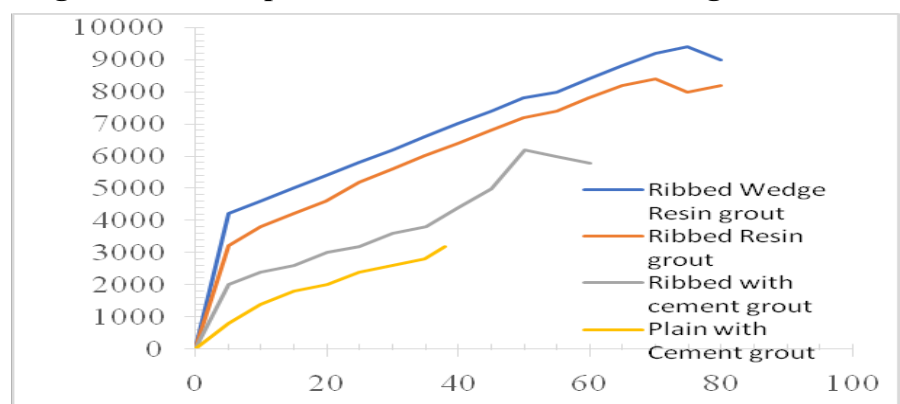

Fig 6: Behavior of Rock Bolts on Pull Out Test

\section{Selection and Geometry of Rock Bolt (RB)}

Rock bolt support system works on bond strength in between bolt to grout and grout to rock/soil. Failure mechanism of rock bolt shows the advancement into the rock bolting system. Pull out test give the actual bonding capacity of rock bolt and numerical formulation gives the support stiffness, maximum load bearing capacity and load deformation constant for RB head. Bonding strength of RB has three component cohesion, friction and mechanical interlocking. Plain rock bolt having very low frictional /bonding strength in between 
bolt and grout and it will fail easily. Presently in construction process such type of bolting is not used but research shows the pull-out test on plain bar give the value of confining pressure i.e. test used for designing/ modeling purpose.

Ribbed bar provides the high frictional and mechanical interlocking in between bolt and grout and play an important role in bonding capacity in rock bolting. Previous experimental studies shows that, the bolt surface profile plays an important role in gathering shear resistance in between bolt and grout and effect of surrounding rock formation.

\section{Drilling and Blasting work}

Design methodology is based on the conventional methods like drilling blasting, rock bolting and grout anchors and introduction of shotcreating as support member to excavated boundary. Approach of NMT and NATM used for support design includes drilling blasting work.

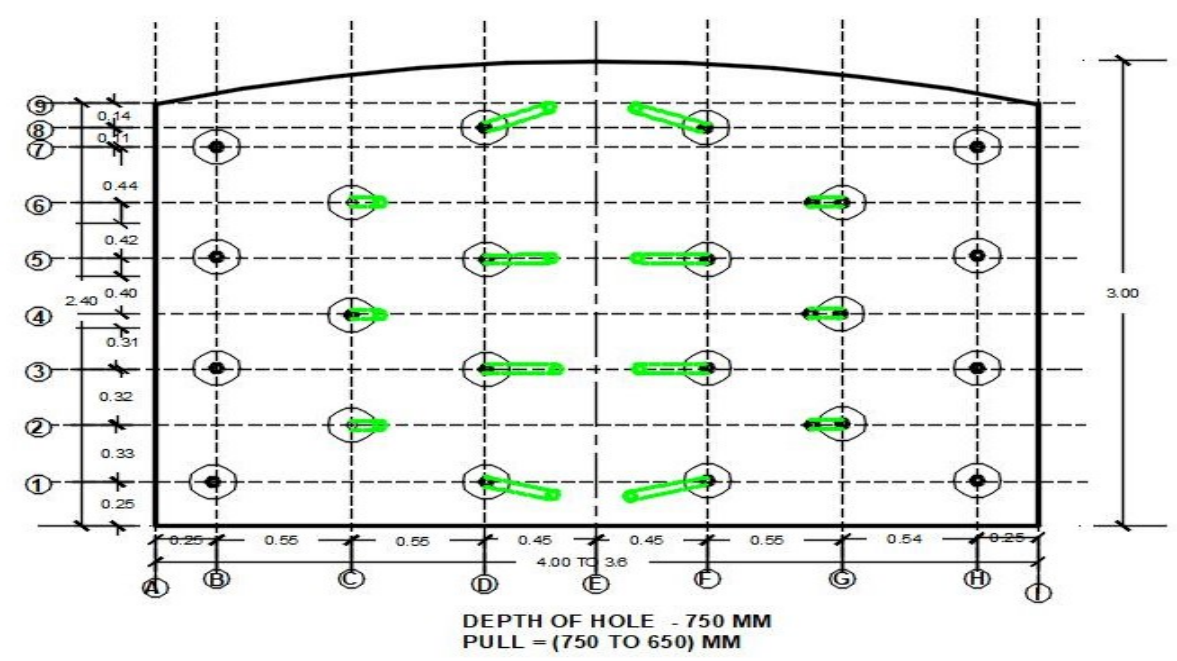

Fig 7: Drilling and Blasting Pattern at Moil Munsar Mine

\section{Cost Comparison}

On the basis of experimental work at Munsar Mine of MOIL limited shows the actual cost comparison on the year 2017-18, which also shows the economy, time duration.

\begin{tabular}{|l|c|c|}
\hline \multicolumn{1}{|c|}{ Activities } & $\begin{array}{c}\text { Conventional Concreting } \\
\text { work }\end{array}$ & $\begin{array}{c}\text { Shotcreating with NMT } \\
\text { and NATM }\end{array}$ \\
\hline Cost for $1 \mathrm{Rmt}$ & Rs. 73,788 & Rs. 56, 720 \\
\hline Cost for 10 Rmt & Rs. 7, 37, 880 & Rs. 5, 67, 200 \\
\hline Time duration for $10 \mathrm{Rmt}$ & 30 to 35 Day & Rs. 10 to 12 Days \\
\hline
\end{tabular}

\section{Table 3: Time and Cost Comparison}

\section{Design used at Munsar Mine of MOIL Limited on Experimental Area:}

Design calculation done as per IS (Indian standard) and check through RMR and Q-system. Same drift also checked on software like Rocscience and Ansys.

1. Short anchors $(\mathrm{RB})$ of $1.80 \mathrm{~m}$ long with $1 \mathrm{~m}$ centre to centre

2. Long anchors $(\mathrm{CB})$ of $5.0 \mathrm{~m}$ long with $2 \mathrm{~m}$ centre to centre

3. Primary layer of shotcrete of 25 to $50 \mathrm{~mm}$ with smooth finish to drift

4. Steel wire mesh of $1.5 \mathrm{~mm}$ size of wire with $60 \mathrm{~mm} \times 60 \mathrm{~mm}$ grid

5. Final layer of shotcrete of 100 to $125 \mathrm{~mm}$ of M 30 use of modified polymer compound

\section{Discussion}

Most of the underground mines are using conventional drilling and blasting method along with cut and fills system. At places in haulage roads or cross cuts where the geological conditions are unfavorable, concreting is being done. At all other locations, steel and cable bolts are being adopted. These methods specially concreting is not only time consuming but also uneconomical from mine operations point of view. It increases the cycle time and affects the productivity. The requirement of Ore and Coal is increasing every year. Adaptation of NMT and 
NATM will simplify the support system and increase the rate of development work inside the underground with economical, safety and improvement of ventilation. Such an increase in production rates lead to substantial change in the current method of production. However NMT and NATM will require the expertise understanding of Geotechnical, Geology and Environment for its effective and efficient applications.

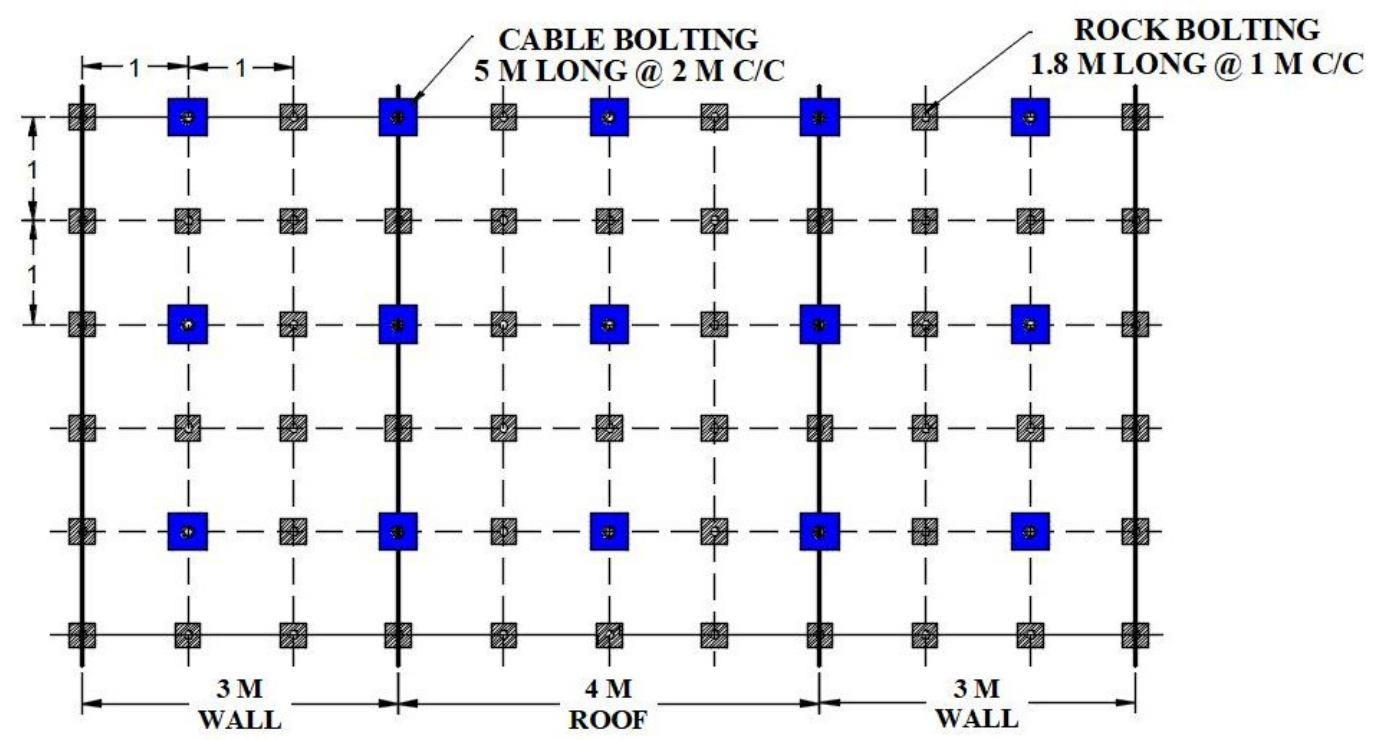

Fig 8: Design Plan of RB and CB

\section{Conclusions}

The requirement of manganese is increasing every year and MOIL is expected to produce two million tons by the year 2020. Such an increase of production rates warrants substantial changes in the current practices of production. In the present study, an attempt has been made in this direction. It is suggested to do the construction activity adopting shotcreting supports system wherever possible and feasible, confirming to the NMT or NATM. It is fast, economical, safe approach and gives smooth surfaces. With experience better results are expected than what we have reported in the study. In general, rock cores are available in mines, if the inhouse testing facilities are developed within MOIL then scientific analysis can be done on our own as MOIL do have sufficient expertise in the field.

\section{Future Scope}

Majority of MOIL Mines are underground mines and depth of underground increasing every year. Adaptation of NMT and/or NATM will simplify the support system and increase the rate of development works inside the underground with optimal economy, safety and environmental friendly manner. Environmentally means proper lining of drift will increase the ventilation of underground due to smooth surface and increased size of drift. However, to make this construction technique more popular and adoptive, more detailed investigation / examination of other necessary allied properties (beyond scope of our work) of the ground, geology, ground water, etc. may be planned and the study can be carried out in that direction. This paper suggests an approach towards the possible adoptability of NATM / NTM techniques in mine constructions.

\section{Acknowledgement}

We are thankful to the Chairman cum Managing Director, MOIL and Director (Production \& Planning), MOIL for the consistent motivation, support and necessary permissions to carry out this research activity.

\section{References}

1. Purwanto, Wahyudi, S.Shimada, SasaokaT, Wattimena R 2014. Support design of Underground cut and fill mine by using Hybrid Numerical empirical model. Geology and Geoscience 3/2: 1-8.

2. H.Guo, N.I. Aziz and L.C. Schmidt 1993. Rock fracture toughness determination by the Brazilian test. Engineering Geology 33: 177-188.

3. Charlie C. Li. Principles of Rock bolting design. Rock Mechanics and Geotechnical Engineering 1.9: 396414.

4. Evert Hoek, David F 1987. Support in underground hard rock mines.Underground support system. 35:1-6. 
5. MengQingbin, Han Lijun, Sun Jingwu, Min Fengqing, Feng wei, Zhou Xing 2015. Experimental study of bolt- cable combined supporting technology for the extraction of roadway in weakly cemented strata. Mining Science and technology 25:113-119.

6. MehrdadBastami, KouroshShahriar, Mostafa Ghadimi 2017. Verification of analytical model of fully grouted rock bolt based on pull-out test. Sciencedirect191:1068-1074.

7. M.M. Madan 2015. 5P system of excavation in extremely weak and flowing rock mass. ISRM (India) 4: 3-8.

8. IuriiKhalymendyk, Anna Brui, Anatoli Baryshnikov 2014. Usage of cable bolt for gateroad maintenance in soft rock. Sustainable Mining 13(3):1-6.

9. Liang Cheng, Yidong Zhang, Ming ji, KalZhang, Minglei Zhang 2016.Experimental study on bolt parameters on the bearing characteristics of reinforced rock. Springer Plus 5:866 : 1-15.

10. Dinh PhucHoang, GuangLi Xu, Zhi Peng Li. Effect of Deformation and failure characteristics of rock under confining pressure test induced rock burst. EJGE, 21: 9961-9972.

11. Wu Tao, Cao Chen, Han Jun, Ren Ting 2017. Effect of bolt rib spacing on load transfer mechanism. Mining science and technology.27: 431-434.

12. IS 11309-1985 (Reaffirmed 2001). Method for Conducting Pull out test on Anchor bar and rock bolts.

13. IS 13219-1992 (Reaffirmed 1999). Rock bolts for mine (Cement grouted)- General Requirement.

14. IS 13517 - 1992 (Reaffirmed 1999). Rock Bolts- Resin type-Specifications.

15. IS 14448: 1997 (Reaffirmed 2012).Codes for Practice for reinforcement of rock slopes with plain wedge failure

16. IS 1943-1979 (Reaffirmed 2001).Method for determination of unconfined compressive strength of rock material

17. IS 9321-1979 (Reaffirmed 2001).Method for determination of modulus of elasticity and Poisson's ratio of rock material in Uniaxial Compression

18. IS 10082-1982 (Reaffirmed 2001).Method for test for determination of tensile strength by indirect tests on rock specimens

19. EM 1110-2-2005.Introduction of Shotcrete applications.

20. IS 9012-1978 ((Reaffirmed 2002).Recommended practice for shot creating 